\title{
UMA SUCINTA EXPOSIÇÃO DA NOÇÃO DE HONRA NO BUSHIDÔ DE NITOBE
}

\author{
Gabriel Pinto Nunes ${ }^{1}$
}

Resumo: A honra entendida como virtude ou como invariante axiológica é um termo que acompanha a civilização humana desde priscas eras e possui importante papel na formação de si do sujeito moderno. Sua existência leva ao questionamento de arquétipos que expliquem como um termo pode ser universalizado entre os homens em diferentes épocas e em diferentes contextos históricos e com forte conotação no agir do sujeito. Neste pequeno artigo exporemos uma possível leitura sobre este termo dentro da ética moderna japonesa focando na obra Bushido - The Soul of Japan (1900) de Nitobe Inazo (1868-1933), a qual apresenta uma releitura do código de conduta dos samurais voltada à divulgação dos valores nipônicos modernos à comunidade internacional do século XX.

Palavras-chaves: honra, ética, bushidô, Japão, Meiji.

\begin{abstract}
The honor understood as a virtue or as axiological invariant is a term that comes human civilization since ages pristine and has an important role in the formation of the modern subject itself. Their existence raises the question of archetypes to explain how a term can be universalized among men in different times and in different historical contexts and with a strong connotation in the act of the subject. In this small article we will expose a possible reading about this term inside the modern ethic Japanese focused in the work Bushido - The Soul of Japan (1900) of Nitobe Inazo (1868-1933), which presents a reinterpretation of the samurai code of conduct aimed at disseminating modern Nipponese values to the international community of the twentieth century.
\end{abstract}

Keywords: honor, ethic, bushido, Japan, Meiji.

\section{Introdução - A Honra no Ocidente}

Do momento em que o sujeito passa a ter consciência da existência do outro, entendido como um indivíduo que compartilha do mesmo espaço e que

1. Mestre em Literatura, Língua e Cultura Japonesa e Bacharel em Filosofia pela FFLCH-USP, shimeman@ gmail.com 
tem liberdade no mundo, se estabelece uma convivência que pode ser pacífica ou conflituosa. Estas relações dentro da sociedade podem ser condicionadas pela moral, a qual reúne os valores comuns dos envolvidos. Este tipo de interpretação do surgimento do convívio humano tem como base que todo e qualquer homem é, por excelência, um ser social que se completa no convívio com os outros.

Um dos principais valores morais e muito usado nas artes e na literatura, a honra está presente nos povos do leste ao oeste do globo terrestre, independentemente da época. Oposto à honra, temos a desonra, entendida como uma falta à honra individual e a vergonha, esta motivada pelo próprio sujeito pela realização de alguma atitude que prejudica a própria imagem. Taille (2002) faz uma abordagem sobre o sentimento de vergonha e sua relação com a moralidade levando em consideração o seu papel para formação dos juízos do ser e do outro. Em uma das abordagens baseadas em Ernst Tugendhat, mostra que por meio dos valores morais é possível preservar a identidade do eu, ou seja, o sujeito é constituído no campo das relações sociais regradas por valores comuns a todos. Ainda segundo a leitura de Taille, a honra e a vergonha possuem papel fundamental na construção da identidade do eu, pois são conceitos que somente existem a partir do olhar do outro. Como dito por Sartre (2003, p. 290): “A vergonha é vergonha de si diante do outro". Contudo, tal ideia que a vergonha ou honra do sujeito depende obrigatoriamente da visão do outro não é recente, sendo possível encontrarmos uma versão dela na Retórica de Aristóteles (ARISTÓTELES, 2003) quando afirma que: "A vergonha é ligada a nossa própria opinião". Peristiany enfatiza:

\begin{abstract}
A honra e a vergonha são valorizações sociais e partilham, portanto, da natureza de sanções sociais: quanto mais monolítico é o júri mais severo é o julgamento. Honra e vergonha são dois polos de uma valorização. São a reflexão da personalidade social no espelho dos ideais sociais. O que é específico dessas valorizações é serem usadas como padrão de medida do tipo de personalidade considerado representativo e exemplar de uma dada sociedade. Quem satisfazer esses padrões pode, sem cair em desgraça, quebrar outras regras consideradas menores que as da honra. (PERISTIANY, 1965, p. 3).
\end{abstract}

A presença da honra no mundo ocidental nos remete à antiguidade, especialmente à Ilíada de Homero iniciada com a ira de Aquiles despertada por uma desonra feita por Agamêmnon. Esta passagem nos mostra a honra como parte formadora do caráter do sujeito e também a concepção de que as ações do sujeito são regradas por ela. Um dos meios para que a honra (timé) ligada ao nome se perpetue é pelo kleos, a glória que possibilitará que todas as gerações futuras se lembrem dos feitos do passado. Tanto o vínculo estabelecido entre o nome do sujeito e a noção de honra não possuíam interpretações imutáveis no ocidente, elas se adaptaram ao longo dos anos, como notamos nos povos ocidentais os quais no século XVII criaram os primeiros códigos de honra escritos, abandonando a fundamentação dela pela 
tradição oral. Esta transformação viabilizou a entrada da honra na jurisprudência, ou seja, qualquer sujeito que se sentisse difamado poderia recorrer ao tribunal o qual analisaria a situação, julgaria e forneceria uma sentença segundo o código escrito. Porém, a existência deste tribunal é condicionada à existência do estado que mantém um sistema jurídico funcional e impõe as decisões do tribunal aos réus, além de um código que possa ser interpretado. Vemos um gradativo distanciamento da timé para a honra que se constituía ao longo dos anos, contudo tal mudança era o reflexo das mudanças na própria sociedade ocidental, como nos mostra Baroja:

\begin{abstract}
"Honra tanto quiere dezir, como adelantamento señalado con loor, que gana ome por razon del logar que tiene, o por fazer fecho conoscido que faze, o por bondade que em el ha". Essa é a definição que se encontra nas Partidas, código castelhano do séc. XVII, cuja importância é talvez maior de um ponto de vista ético e filosófico que dum ponto de vista estritamente jurídico. A honra fundamenta-se na bondade própria e constrói-se mediante ações do próprio ou daqueles que o geraram numa posição (logar.) e não noutra. (in PERISTIANY, 1965, p. 66)
\end{abstract}

Se na antiguidade ocidental não houve um código escrito sobre a honra, estando o seu entendimento mais próximo da interpretação subjetiva do ser sobre um conteúdo transmitido oralmente, na Idade Média encontramos a redação destes códigos, assumindo um papel jurídico, até então inédito, possibilitando que a honra do sujeito pudesse ser mensurada ou quantificada, segundo Baroja.

Pode, pois dizer-se que na Idade média, existem, ou coexistem dois sistemas de conceptualizar honor e honra. Um, que parte de princípios religiosos, filosóficos e jurídicos e que é geral. Outro, que parte de situações de facto dentro da estrutura social. Ajustaram-se os dois sistemas um ao outro de forma peregrina, demonstração plena de que o princípio da contradição não rege a vida das sociedades, mas que a própria contradição está no ser das coisas (el ser de las cosas) como pretenderia um hegeliano. (in PERISTIANY, 1965, p. 66.)

\title{
2. A honra para o Japão moderno
}

A concepção de honra não é exclusividade do mundo ocidental. Nas sociedades antigas do extremo leste asiático temos as chamadas culturas da vergonha, nas quais todo o tecido social é constituído a partir das noções de honra e vergonha. Encontramos sistemas de pensamento os quais privilegiam a organização social e a moral, como o confucionismo ${ }^{2}$ que vem sendo tomado por leitores ocidentais

2. Confúcio morreu em 479 a.C. aos 72 anos de idade. Nos seus tratados estão as doutrinas fundamentais do confucionismo: a essência do humano é a boa vontade; o homem deve humanizar-se, pelo cultivo de suas forças morais, se não se desvia do Curso (道 dào); a partir da base familiar deve o homem estender o amor 
como uma doutrina moral que distinguia a vida mundana da ascética devido à busca por um ideal moral perfeito que possibilitaria a existência de um homem superior. Nele há o favorecimento do convívio social com o objetivo de atingir a plenitude de caráter por meio da moral. Nas culturas da vergonha que têm como base o confucionismo é dada grande importância à honra como acontece nas sociedades do ocidente. Sobre este ponto, temos na obra $O$ Crisântemo e a Espada:

Um homem idôneo sente com a mesma intensidade os insultos tanto quanto os benefícios que recebe. Constitui virtude pagar a um ou a outro. Ele não separa os dois, como fazemos nós chamando a uma agressão e ao outra não-agressão. (...) "O mundo está virado", dizem eles enquanto um insulto, estigma ou derrota não seja revidado ou eliminado. Um homem decente deve tentar pôr o mundo novamente em posição de equilíbrio. É a virtude humana e não um vício bem humano. (BENEDICT, 2007, p. 126.)

A sociedade japonesa da virada do século XIX para o XX pode ser tomada como exemplo da cultura da vergonha. Aparentemente, o isolamento político auto imposto no Período Tokugawa (德川時代 - 1603-1868), conhecido como Sakoku ( ), favoreceu o florescimento da honra confucionista. No arquipélago o principal sistema de pensamento foi o confucionismo que se difundiu dentro da

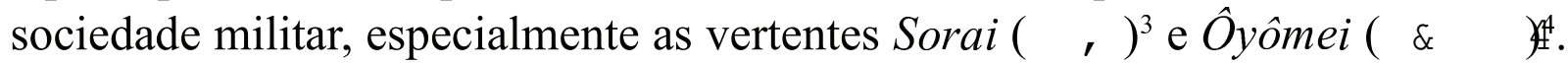
Por este motivo foi fácil o surgimento de códigos de conduta para regrar a vida em sociedade entre as camadas sociais. Um deles foi o código dos guerreiros japoneses, o bushidô ( $S \neq \gg$, difundido após o Período Meiji ( 4 ○ 6 1868-1912).

Os países ocidentais vieram a conhecer mais sobre este código de conduta com a publicação da obra Bushido - The Soul of Japan de Nitobe Inazo ( e 6 " ! ? B - 1862-1933), em 1900. O objetivo da obra foi divulgar a moral japonesa ao

filial a todos; a harmonia entre o homem e a mulher constitui a saúde social; os homens nascem com as mesmas aptidões; a política é o campo de efetivação da moral; na vida pública a informação deve coincidir com a efetivação; a investigação das coisas principia pela retificação da mente e resulta no conhecimento do bem inato, princípio e fim da ação moral. (SPROVIERO, 1989, p. 9)

3. A vertente Zhu Xi (Chu Hsi 1130-1200), difundida no Japão principalmente por Ogyu Sorai (1666-1728), pregava a bondade inata aos homens mesmo que estes agissem imoralmente, pois o cultivo da moral traria claridade à força vital $(q i)$ do homem.

4. Esta vertente fruto do pensamento de Wang Yang Ming (1472-1529) influenciou diretamente Motoori Norinaga (1730-1801), que afirmou ser o conhecimento inato às pessoas, desta forma, todos saberiam a diferença entre o bem e o mal.

5. Nitobe desde a sua infầncia recebeu uma educação ocidentalizada devido à abertura dos portos japoneses após a Restauração Meiji. Na adolescência viajou para os Estados Unidos para fazer pós-graduação e na volta publicou a sua principal obra: Bushido - The Soul of Japan. Em seus textos podemos notar a influência de Carlyle e Burke, além do discurso cristão em detrimento das religiões comuns no Japão. Na década de 1920 foi o representante japonês na Liga das Nações, instituição que precedeu a Organização das Nações Unidas (ONU). Renunciou ao cargo por divergências com o governo nipônico. 
ocidente para que houvesse uma aproximação cultural, além de contribuir para a formação de uma identidade nacional japonesa, a exemplo do que as nações europeias fizeram ao longo do século XIX. Por meio desta obra, o autor mostrou aos olhos ocidentais que aquilo entendido como moral e honra no Japão era similar ao que se desenvolveu na Europa, como escreve Nitobe no capítulo inicial:

\begin{abstract}
Bushido, then, is the code of moral principles which the knights were required or instructed to observe. It is not a written code; at best it consists of a few maxims handed down from mouth to mouth or coming from the pen of some well-known warrior or savant. More frequently it is a code unuttered and unwritten, possessing all the more the powerful sanction of veritable deed, and of a law written on the fleshly tables of the heart. It was founded not on the creation of one brain, however able, or on the life of a single personage, however renowned. It was an organic growth of decades and centuries of military career. $(1972$, p. 25.)
\end{abstract}

A honra entendida como virtude ou como moralidade existiu em diversas sociedades humanas ao longo do tempo e diversas interpretações podem ser dadas ao seu significado. Contudo, à medida que a sociedade evoluiu, nota-se que tal processo acompanhou um esvaziamento do conceito de honra. Em outras palavras, em situações históricas recentes houve a tentativa por diferentes setores da sociedade em reavivar a virtude da honra em um sentido muito próximo daquele como se cristalizou no imaginário, porém o que se obteve foi uma nova versão da honra que se analisada profundamente possui pouco vínculo com o modelo escolhido como referencial ${ }^{6}$.

Akutagawa Ryunosuke ${ }^{7}$ ( $川$ 龍之介-1892-1927) em seu conto O Lenço (Hankachi-手巾) de 1916, compartilhou o ponto de vista de Nitobe sobre a artificialidade existente nas relações sociais modernas as quais não zelam pela evolução da sociedade. A crítica é centrada na preocupação exacerbada e desnecessária para manter a aparência, tomado por eles como evidência do esvaziamento do conceito de etiqueta. O mesmo se estende a noção de honra, visto ser ela uma valorização, se a basearmos em mera aparência, o julgamento que o outro fará poderá ser falso e não corresponder ao que de fato acontece. Taille nos diz:

6. Jean-Michel Belorgey, em seu artigo Grandeza e servidões da transgressão, faz uma leitura sobre a honra dos samurais, os quais foram utilizados como exemplo de ideal ético a ser seguido pelos cidadãos japoneses no início do século XX:

"Um samurai", diz o Bushido, o código de honra do samurai, "não tem duas palavras. Ele não tem dois mestres. Ele satisfaz à honra derramando seu sangue, como a cerejeira deixa cair suas flores". (in GAUTHERON, 1992, p. 151-152.)

7. Sua produção bibliográfica se concentra no período Taishô e seus contos têm enredos que tratam da obscuridade da natureza humana. 
(...) a honra corresponde ao sentimento do próprio valor moral. Age-se de forma honrada quando se procura manter ou aumentar o valor moral presente nas representações de si. Mostra-se ser sensível à honra quando, uma vez cometido uma ação que contraria a moral, sente-se vergonha. É neste sentido que honra pode ser sinônimo preciso da vergonha moral (prospectiva e retrospectiva). Todavia, como seu peso semântico é carregado de várias interpretações, notadamente com ambiguidades (honra precedência versus honra virtude, honra exterior versus honra interior, agir por honra versus agir com honra - ver La Taille, 2000), talvez seja prudente empregar outro conceito, que se encontra na obra de Rawls (1971), e que pode ter o mesmo sentido: o autorrespeito. Assim teremos autoestima quando os valores associados às representações de si forem estranhos ou contrários à moral, e teremos honra ou autorrespeito quando tais valores forem morais. E este autorrespeito corresponde, como todo nosso texto procurou mostrar, à força motivacional que leva a pessoa a agir, e a pensar moralmente. Tal tese pode ser sintetizada como o propõe Le Doeuf (1993): respeitar os outros e respeitar a si próprio implicam-se reciprocamente.

(TAILLE, 2002, p. 23.)

A ambiguidade entre a honra interior e exterior aparentemente é mais latente na sociedade japonesa, pois como exposto por Ruth Benedict (1887-1948) em sua obra $O$ Crisântemo e a Espada, publicada em 1946, dentro da sociedade japonesa são muito bem definidos os assuntos da esfera privada e pública. Por exemplo, quando um sujeito deixa de cumprir algo que seja sua obrigação e que beneficie o grupo, ele será acometido pela vergonha perante o grupo por não ter cumprido o que se esperava dele. A vergonha que sente é compartilhada com os seus semelhantes ou familiares. Em alguns casos esta falta cometida somente poderia ser reparada com o suicídio, ou seja, oferecendo a própria vida como moeda no pagamento desta dívida adquirida com o outro. Com a morte não só a reputação do sujeito estaria limpa, como de toda a sua família.

\section{O Suicídio como correção da Honra}

O suicídio praticado no Japão do período Tokugawa é chamado de haraquiri (腹切) ou seppuku (切腹), e consiste no ato de retirar a própria vida com a exposição das entranhas para corrigir um mal cometido ou reparar a honra da família. Nitobe em sua obra expõe-nos que no Japão, por causa do Bushidô, tal prática era comum por não haver um tribunal que julgasse o mérito de questões relacionadas à honra do sujeito. O problema era que por não existir um código escrito que definisse o que era a honra, pois a sua noção era transmitida oralmente, possibilitou diversas interpretações baseado em fatos e experiências de cada indivíduo. Desta forma, tornou-se impraticável a formalização universal do conceito por sempre depender de elementos particulares. 
Death involving a question of honour, was accepted in Bushido as a key to the solution of many complex problems, so that to an ambitious samurai a natural departure from life seemed a rather tame affair and a consummation not devoutly to be wished for. (NITOBE, 1972, p. 93).

Desta forma, tornou-se impraticável a formalização universal do conceito por sempre depender de elementos particulares. Contudo, se tomarmos como referência uma posição moderna sobre a questão da jurisprudência, veremos que a inexistência do código escrito não invalida o entendimento geral sobre uma noção em particular, assim como a sua interpretação. A teoria da tridimensionalidade do direito (REALE, 1968) afirma haver um processo no qual, com o decorrer do tempo, os valores dentro do grupo humano se modificam, obrigando à modificação contínua da norma para se adaptar aos novos paradigmas que se constroem. Por isso, este processo histórico no qual todos os indivíduos estariam inseridos, mesmo que sem consciência plena do processo como um todo por ser independe da vontade particular, as interpretações que surgem sobre a noção de honra estariam todas necessariamente restritas ao mesmo sentido do valor de honra. Ou seja, todos os membros de um determinado grupo humano, se convivessem conjuntamente em um determinado local por um período de tempo determinado, inevitavelmente compartilhariam da mesma noção, ou valor, de um conceito. À luz desta interpretação histórica temos a garantia de que é possível a universalização de um conceito dentro do grupo humano.

Neste caso é válido que, segundo a interpretação pessoal, em um sistema no qual se permite ao indivíduo tirar a própria vida se entender ser este a melhor maneira para corrigir a desonra. Nitobe tentou argumentar que tal ato não era bárbaro, mas o reflexo da responsabilidade que o indivíduo assume perante a sociedade por entender a sua posição dentro dela e, mais importante, o seu papel.

Among a savage tribe which has no marriage, adultery is not a sin, and only the jealousy of a lover protects a woman from abuse; so in a time which has no criminal court, murder is not a crime, and only the vigilant vengeance of the victim's people preserves social order. (NITOBE, 1972, p. 100).

A honra é a valorização do outro sobre o indivíduo, no qual ambos devem compartilhar do conhecimento de suas posições dentro da hierarquia social. A história nos mostra que o estado japonês durante o Período Tokugawa, interferiu na execução do haraquiri por haver o descontrole nas decisões de práticas suicidas. Temos a honra quase como um instrumento regulador das relações estabelecidas entre os homens, dependente de toda estrutura social previamente existente.

Both of these institutions of suicide and redress lost their raison d'etre at the promulgation of the Criminal Code. No more do we hear of romantic adventures of a 
fair maiden as she tracks in disguise the murderer of her parent. No more can we witness tragedies of family vendetta enacted. The knight errantry of Miyamoto Musashi is now a tale of the past. The well-ordered police spies out the criminal for the injured party and the law metes out justice. The whole state and society will see that wrong is righted. The sense of justice satisfied; there is no need of kataki-uchi. If this had meant that "hunger of the heart which feeds upon the hope of glutting that hunger with the life blood of the victim," as a New England divine has described it, a few paragraphs in the Criminal Code would not so entirely have made an end of it. (NITOBE, 1972, p. 102).

Porém, devemos ter cuidado na generalização da honra por meio deste ponto de vista jurídico. Não podemos tomar a honra como uma invariante axiológica, pois isto seria afirmar que a honra é uma e a mesma ao longo dos tempos. Como exposto acima os valores se modificam segundo os costumes dos homens ao longo do tempo e a interpretação da honra para os medievais, para os samurais e para os modernos são diferentes. A justificativa se encontra no sistema de poder estabelecido dentro da sociedade, ou seja, a honra é interpretada segundo o posicionamento da aristocracia e do poder político vigente. Mais uma vez Belorgey nos diz:

\begin{abstract}
A honra-virtude pode, em certas épocas, dizem, se situar em oposição ao Bem comum ou conveniente, e contudo ser reconhecida como tal, por mais chocante que isto possa parecer hoje - a competência para julgá-la estando estreitamente ligada aos sistemas de poder ou de precedência então em vigor. Ainda assim ela se achava estabelecida na existência de uma comunidade da honra, possivelmente obscena, mas não imaginária. (in GAUTHERON, 1992, p. 157).
\end{abstract}

\title{
4. O on e o giri na Honra Japonesa
}

A honra nipônica foi popularizada graças aos samurais $^{8}$ e seu oposto, a vergonha, representa a falta de compostura por agir contrariamente ao proposto pelo bushidô, ou pela difamação do caráter por outrem.

Segundo a Retórica de Aristóteles por meio da vergonha é possível obter várias informações acerca da honra: "Eis, portanto, o que concerne à honra; sobre a impudência é evidente que dos contrários tiraremos abundantes premissas". (ARISTÓTELES, 2003, p. 47). O ponto mais importante sobre ela se dá com a

8. “Todo lo que se desarrolló más allá del concepto de honor feudal en cuanto a sublimación de la vida impulsiva y emocional ha sido indiscutiblemente obra suya. También aquí el budismo conservó el frío temple de la soteriología intelectual india, que se fundió con la norma confuciana de la "contención" y el "decoro", interpretada en Japón nuevamente en el sentido feudal, en el ideal del gentleman basado en la dignidad del gesto y la distancia sentimental del europeo, suelen sentirse los Japoneses cultos representantes de este ideal." (WEBER, 1987, p. 290-291). 
colocação que como virtude depende exclusivamente do olhar do outro e a sua condição de juízo valorativo impossibilita que seja uma invariante axiológica. Como em outras virtudes, a valorização não é proveniente do próprio indivíduo ao se julgar honrado ou corajoso, mas do julgamento do outro que vive no mesmo meio social e compartilha dos mesmos costumes. Para que o indivíduo seja valorizado necessita ser objeto para o outro, isto é, o outro o veja como um objeto para atribuir valor. Sobre a honra e vergonha Peristiany nos diz:

\begin{abstract}
A honra e a vergonha são valorizações sociais e partilham portanto da natureza de sanções sociais: quanto mais monolítico é o júri mais severo é o julgamento. Honra e vergonha são dois polos de uma valorização. São a reflexão da personalidade social no espelho dos ideais sociais. O que é específico dessas valorizações é serem usadas como padrão de medida do tipo de personalidade considerado representativo e exemplar de uma dada sociedade. (PERISTIANY, 1965, p. 3).
\end{abstract}

Segundo Nitobe, as fabulosas histórias de samurais não deviam ser entendidas como verdadeiras, pois são um instrumento de intimidação das pessoas comuns para enfrentarem os samurais. Assume que admitir a veracidade delas mostraria os heróis como seres impacientes os quais não saberiam ignorar ofensas banais, sinal claro de desequilíbrio. A honra não deveria ser buscada no mundo, mas dentro do próprio homem, esse é o ponto em comum de Nitobe e Mêncio ${ }^{9}$, a crítica àqueles que saem pelo mundo em busca de renome pensando que a virtude se resume apenas à fama, por confundi-la com riqueza e prestígio.

O pretendente à honra tem que fazer com que os outros aceitem a sua avaliação que faz de si próprio, tem que conseguir reputação, pois, no caso contrário, a pretensão passa a ser simples vaidade, objeto de ridículo ou desprezo - mas por parte de quem? $\mathrm{O}$ moralista tem o direito de arbitrar as pretensões à honra de acordo com os seus próprios valores [e muitos dos tratados de honra são, na realidade, tirados contra os costumes da época], mas os cientistas sociais ocupam-se de factos e processos de identificação: como, com que fundamento e por quem é a honra identificada? (PERISTIANY, 1965, p. 14).

Nesta passagem Peristiany comprova a argumentação de Nitobe, de que aquele que almeja a honra a consegue pelo outro, porém se a busca for motivada pela vaidade será desprezível e passível de reprovação. Devemos entender que a vaidade, segundo a construção de Nitobe, é algo prejudicial ao caráter do homem, pois o incentivaria a fazer escolhas erradas e provavelmente a ignorar colocações básicas do bushidô.

9. Mêncio (370 a.C. - 289 a.C,) foi um filósofo chinês considerado herdeiro intelectual de Confúcio. 
O conceito de honra utilizado por Nitobe pode ser associado a timé grega. Tomando como referência Vernant (2002), este nos apresenta uma construção da honra grega através do olhar do outro, isto é, através do convívio social o indivíduo é obrigado a provar ter merecimento da timé. Observamos que uma vez alcançada a honra, o indivíduo gozaria de certos privilégios públicos sendo-lhe permitido participar de uma determinada aristocracia (aristói). Há muitos pontos em comum entre a honra japonesa (renchishin - 廉恥心) e a timé, uma delas é a glória imortalizada (glória imperecível - kléos áphthiton) pela morte corajosa (agathòs anér) no campo de batalha, como ocorreu com Aquiles:

\begin{abstract}
Em uma sociedade de confronto na qual, para ser reconhecido, é preciso derrotar os rivais em uma competição incessante pela glória, cada indivíduo está colocado sob o olhar do outro, cada indivíduo existe por este olhar. Ele é o que os outros veem dele. A identidade de um indivíduo coincide com sua avaliação social: da derrisão ao louvor, do desprezo à admiração. Se o valor de um homem permanece assim ligado à sua reputação, toda ofensa pública à sua dignidade, todo ato ou comentário que atinge seu prestígio serão sentidos pela vítima, enquanto não forem abertamente reparados, como uma forma de rebaixar ou de destruir se ser, sua virtude íntima e de consumir sua queda. Desonrado, aquele que não conseguiu que o homem que o ofendeu pague pelo ultraje perde, com sua timé, o renome, o lugar na hierarquia e os privilégios. Separado das solidariedades antigas, afastado do grupo de seus pares, o que resta dele? Caído abaixo do vilão, do kákos que ainda tem seu lugar entre as hostes do povo, torna-se um errante, sem país ou raízes, é um exilado desprezível, um homem sem nenhum valor, para retomar os termos de Aquiles ofendido por Agamênon (Ilíada, IX, 648eI293). (VERNANT, 2002, p. 207-208).
\end{abstract}

A honra, portanto, pode ser entendida como a elevação de posição dentro da sociedade, desde que a motivação não seja a vaidade e ganância. Contudo, a interpretação da escolha do caminho para obtê-la depende do sistema de valores no qual se encontra o indivíduo e da elaboração dos juízos, como afirma Pierre Bourdieu (in Peristiany, 1965, p. 172).

Um ponto de honra é o fundamento da moral próprio de um indivíduo que se mede sempre sob o olhar dos outros, que tem necessidade dos outros para existir, porque a imagem que se forma de si próprio não pode ser diferente da imagem de si que é devolvida pelos outros.

E, um sistema de valores e, Segundo Julian Pitt-Rivens:

Um sistema de valores nunca é um código homogéneo de princípios abstratos a que obedecem todos os participantes de uma dada cultura e que, pode ser extraído de um informador com o auxílio de um conjunto de perguntas hipotéticas, mas uma coleção de conceitos relacionados uns com os outros e utilizados de maneira dife- 
rente pelos vários grupos sociais definidos por idade, sexo, classe ocupação e etc. nos contextos sociais (e não meramente linguísticos) diferentes que lhes oferecem vários significados" (in PERISTIANY, 1965, p. 28).

Mas no pensamento japonês há alguns conceitos os quais não possuem um correspondente exato no pensamento ocidental. Por exemplo, a concepção de giri, traduzida como senso de dever motivada pela existência de uma dívida social, chamada on (恩). Tanto o on como o giri (義理) não possuem sinônimos nas línguas ocidentais, mas para a honra japonesa são conceitos importantíssimos. Benedict (2007) conseguiu fazer uma exposição moderna sobre o tema, exemplificando o que seria essa dívida social que o indivíduo adquire sem ter plena consciência do fato. Não são dívidas obtidas por empréstimos financeiros, mas dívida que o discípulo adquire por ter um mestre, ou a dívida que um homem adquire por pedir ajuda ao vizinho para arrumar a porta da sua casa. No primeiro caso, independentemente da vontade do indivíduo ele fica em débito com o mestre porque foi aceito como discípulo e consequentemente adquiriu um on, um débito social. No segundo caso a aquisição do débito é voluntária e consciente, ou seja, o indivíduo tem conhecimento de que ao pedir um favor ficará em débito com o outro.

O on é uma dívida que precisa ser paga, mas no Japão todos os pagamentos são considerados como pertencentes a toda uma outra categoria. Os japoneses acham a nossa moral, que confunde essas duas categorias em nossa ética e em nossas palavras neutras tais como obrigação e dever, tão estranha quanto a nós pareceriam os negócios financeiros numa tribo, cuja língua não fizesse separação entre "devedor" e "credor" em transações monetárias. Para eles o débito primordial e sempre presente que se denomina on está a mundos de distância do tenso e ativo pagamento nomeado numa série de outros conceitos. O débito de um homem começa quando ele se empenha ativamente no mister da gratidão. (BENEDICT, 2007, p. 99)

O giri está neste débito que obriga o devedor a pagar o seu credor a qualquer momento. O não pagamento da dívida mancha a reputação ao ponto de estendê-la à sua família. Em alguns casos a única solução para limpar a honra da família se dá com a morte do devedor, não pelas mãos do credor, como sinal de vingança, mas pelo suicídio, o haraquiri. Este é um dos aspectos pelos quais Nitobe trata o suicídio, como exposto anteriormente: quando não há um tribunal sustentado por um Estado para fazer a interpretação de um código escrito, as questões relacionadas ao cotidiano deveriam ser resolvidas pelas próprias pessoas.

\section{Considerações Finais}

No Japão da época de Nitobe, a noção de honra transitava entre o público e o privado, por ser a valorização do outro sobre as atitudes baseados em valores 
comuns ao grupo. O on e o giri eram instrumentos, criações propriamente japonesas para organizar o mundo pela valorização individual. Autores como Peristiany mostram que entre os povos do mediterrâneo a noção de honra era latente, porém não podemos confundir respeito com honra.

É verdade que, na valorização da conduta de uma pessoa, a sua posição social é tomada em consideração. É também verdade que não há posição social nem façanha pessoais que valham a quem não possua os ingredientes de honra. Excelência nestas qualidades (da honra) faz parte da imagem do homem ideal, falta delas abre o caminho ao ostracismo social. O homem ideal e o homem respeitado estão a níveis diferentes da mesma escala de valores. Um estudo dos juízos de valor relacionados com honra e vergonha implica o estudo dos ideais temporais supremos da sociedade e da sua encarnação no tipo ideal de homem. É também um estudo do molde básico da personalidade social. (PERISTIANY, 1965, p. 4).

A honra tanto para ocidentais, mediterrâneos e japoneses foi constituída por valorizações, juízos concebidos por meio dos valores sociais inerentes a cada grupo. Fazer recortes da noção de honra como um conceito universal e buscar nisso relações com a sua existência em outros grupos é ignorar a contribuição dela para a formação da imagem de si que o próprio sujeito constrói por meio da valorização feita pelo outro.

Os movimentos nacionalistas japoneses do início do século XX fizeram o uso de uma leitura particular da noção de honra que concordasse com os anseios imperialistas as quais, indiretamente, ajudaram na composição do bushidô moderno. Se de um lado Nitobe tentava afastar a negatividade do imperialismo aproximando da positividade da cooperação internacional, de outro lado alguns intelectuais criaram discursos para fortalecer o movimento político imperialista. Inevitavelmente, distorções surgiram e aquilo que deveria ser restrita apenas como consequência do giri entre os japoneses foi estendido para aceitar o orgulho narcisista promovido pelo nacionalismo imperialista. O suicídio dos soldados japoneses ao serem capturados pelos inimigos durante a Segunda Guerra Mundial não era motivado pela vergonha, mas devido a propaganda governamental da época. Neste caso temos um exemplo da distorção de um termo por uma posição política.

\section{Bibliografia}

ARISTÓTELES, Retórica das Paixões. São Paulo: Martins Fontes, 2003.

BENEDICT, Ruth. O Crisântemo e a Espada. São Paulo: Perspectiva, 2007.

GAUTHERON, Marie. A Honra: Imagem de si ou dom de si - um ideal equívoco. Porto Alegre: L\&PM, 1992. 
NITOBE, Inazo. The Works of Inazo Nitobe. Volume 1 (Bushido: The Soul of Japan, Thoughts and Essays). Tóquio, University of Tokyo Press, 1972.

PERISTIANY, John G. (Org.). Honra e Vergonha - Valores das Sociedades Mediterrânicas. Lisboa: Fundação Calouste Gulbenkian, 1965.

REALE, Miguel. Teoria Tridimensional do Direito. São Paulo: Edição Saraiva, 1968.

SARTRE, Jean-Paul. O Ser e o Nada. Petrópolis: Editora Vozes, 2003.

SPROVIERO, Mário Bruno. Aspectos da filosofia chinesa: Confúcio e Laozi. Reflexão, São Paulo, v. 41, 1989.

TAILLE, Yves de La. O Sentimento de Vergonha e suas Relações com a Moralidade. In: "Psicologia: Reflexão e Crítica", no 15, 2002, p. 13-25.

VERNANT, Jean-Pierre. Mito e Política. São Paulo: Edusp, 2002.

WEBER, Max. Ensayos sobre Sociología de la Religión II, Madrid: Taurus, 1987. 